\title{
A Comparative Study of Conflicts Experienced Between Immigrant Parents in Canada and in Israel and Professionals in Educational Institutions About Appropriate Responses to Children's Misbehavior
}

\section{Ron Shor}

Hebrew University of Jerusalem

Judith K. Bernhard

Ryerson University

Shor, R., \& Bernhard, J. K. (2003). A comparative study of conflicts experienced between immigrant parents in Canada and in Israel, and professionals in educational institutions about appropriate responses to children's misbehavior. Intercultural Education, 14(4), 385-396.

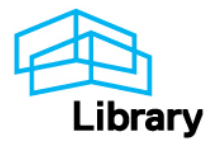




\title{
A comparative study of conflicts experienced between immigrant parents in Canada and in Israel, and professionals in educational institutions about appropriate responses to children's misbehavior
}

\author{
RON SHOR \& JUDITH K. BERNHARD
}

\begin{abstract}
One of the barriers which immigrant parents may encounter in the process of acculturation into their new country is differing expectations about ways in which teachers and other professionals involved in the educational system should relate to their children's misbehavior. To examine the potential sources of conflicts relating to disciplinary measures, a comparative study utilizing a qualitative methodology was conducted with 65 immigrant parents from Latin America in Canada and with 103 immigrant parents from the Former Soviet Union in Israel. The findings indicate that, in the two samples, participants experienced differences between their expectations about the way in which teachers should handle student misbehavior and the actual behavior of the teachers. The differences which the immigrant parents indicated could be characterized primarily as culturally based disagreements about (a) the types of misbehaviors which justify intervention by teachers, (b) the kind of disciplinary measures which should be used, (c) the factors that should be considered when deciding about disciplinary actions, and (d) the lack of sensitivity to the impact of immigration related difficulties on the behavior of children. The immigrants' current expectations of teachers' behavior was based on their experiences in their country of origin, and these were often in contradiction with the common approach in Canada and Israel. Ways of developing reciprocal channels of communication between professionals in schools and kindergartens and immigrant parents are suggested in order to overcome barriers and bridge gaps in communication.
\end{abstract}

\section{Introduction}

Reducing barriers to successful integration of immigrant families with children is a contemporary issue in countries with a high level of immigration. Major conflicts may arise from differences relating to the whole range of child rearing and care issues, with particular emphasis on the ways of handling child misbehavior. In the professional literature relating to immigrant parents' perceptions of their children's 
misbehavior and how to respond to it, the focus has been on how professionals should judge immigrant parents' perceptions of and responses to such behavior. This has occurred because of the increased attention in recent years to issues of child abuse and neglect, and the need for cultural sensitivity on the part of professionals, such as teachers, who are in a position to identify and report such situations in immigrant populations (Shor, 1997). However, an overlooked but important component of reducing barriers to immigrants' integration is developing an understanding of how the immigrants perceive the professionals and their actions in response to their child's misbehavior. Such an understanding would necessarily be based on an awareness of the immigrant group's values and former way of life.

To help understand the experiences and perceptions of immigrant parents as they face these conflicts with professionals in their new country, a comparative study was conducted with parents who immigrated to Canada from Latin America and parents who immigrated to Israel from the Former Soviet Union (FSU). The experience of immigrant parents in Canada and Israel is especially relevant, considering the fact that both Israel and Canada are countries with a high percentage of immigrants and cultural diversity, and both could be considered countries with a Western approach towards education. Both countries are facing challenges relating to reducing conflicts, overcoming barriers hindering successful integration and strengthening their multicultural societies.

When immigrant families migrate to Western countries, they often encounter an orientation to discipline in educational systems different from the one with which they were familiar in their country of origin. This difference may indicate a conflict between their worldview and the common worldview encountered in the educational system in their new country. The concept of worldview helps to illustrate how diverse individuals and cultural groups tend to experience the world in different ways. This relates to differing beliefs, attitudes and values which are not necessarily being expressed overtly, but which are inherent in the life of a culture (Brown \& Landrum-Brown, 1995). Acculturation refers to a process whereby the worldview or behaviors of persons from one culture are modified as a result of contact with a different culture. In this process, the more similar the worldview and customs of the new immigrant to that of the mainstream culture, the fewer changes and conflicts they experience.

One way of understanding the interaction between the worldview of immigrant parents and that of professionals in educational systems is to apply ecological theory (Bronfenbrenner, 1989). This theory emphasizes the linkages and processes taking place between two or more settings containing the new immigrant. It enables assessment of the reciprocal relationship between the important childcare systems in the child's life, including home and school, as well as the interaction of these systems within the larger social and cultural traditions. One of the levels of the environment to which Bronfenbrenner refers is the mesosystem, which is a system made up of two or more microsystems. Taking into consideration the relationship of the mesosystem level of immigrant families with the new educational system is essential. The familiar norms and values of the immigrants may not be applicable, and this may result in differences, which in turn may lead to conflicts and difficulties in collaboration and 
problem solving in educational settings, as well as to difficulties in the immigrants' overall absorption.

The emphasis of ecological theory on the reciprocal relationships among systems illuminates the importance of the mesosystem level of interaction between the school and immigrant families. However, examination of the teachers' perspective when such interaction is discussed has received little attention in the professional literature. This is because the manner in which professionals handle disciplinary issues has long been considered to be an aspect of the acceptable mainstream culture, not needing critical consideration. In addition, little attention has been devoted to the immigrant parents' perceptions and experiences with the school system. They are often viewed as the only individuals who need to be affected and who should undergo acculturation (just as the society from which they emigrate is often being perceived as a society which must change in order to attain modern standards). Slee (1995) raises the concern that in educational systems in Western countries, the notion of discipline is itself seldom explored beyond simplistic neo-Skinnerian behavioral scenarios. Within such a framework, disruptive behavior is reduced to attributions of family dysfunctionality, student pathologies and cultural or class background. Moreover, teachers generally have an uncluttered and ethnocentric view of what is appropriate behavior for children. In the US for example, GapaulMcNicol and Thomas-Presswood (1998) note that in most classrooms teachers have clear and definite expectations of how students should behave, dress, learn, communicate and socialize. Such expectations are essentially pre-reflective and go unscrutinized. Students who do not conform to the teachers' norms are considered to be deviant, behaving 'inappropriately', and are corrected.

The conflicts that immigrants may experience with educational systems in Western countries around disciplinary issues often result from differences between the orientation one finds in the educational systems in their country of origin and in their new country towards discipline, and how these differences might influence their new interactions. Attempts to characterize the differences that immigrants from Latin America may experience must take into consideration the fact that these immigrants make up a diverse cultural group. They differ in factors such as their national origin and history, the particular social formation within each country that shapes age, gender and class relationships, and in the pressures within each country that have led to emigration (Guarnaccia, 1997). Despite these differences, studies of families from Latin America, although they exhibit great variety, illustrate that they typically adhere to a number of values that might be called traditional, in particular the role of authority figures and the concept of collective family good and honor. The family is accepted as a main factor in character building, and Latin American parents believe that schools should be an extension of the family in that respect. Hence, when the parents speak of requiring "educaccion" for their children, they are thinking of character building and moral training, in addition to academic learning (Gallimore \& Goldenberg, 1995). Harwood et al. (1995) reported the presence of what they call "a proper demeanor character" as a socializing goal within the culture of Latin American families. Furthermore, many Latin American parents expect that, like parents, school officials will show a caring attitude towards the students 
(Bernhard \& Freire, 1999). Since the educational orientation in Western countries is focused mainly on academic objectives and not on other objectives, such as moral training and character building, it is most likely that immigrant parents from Latin America will experience conflicts in their encounters with Western educational systems regarding ways of handling disciplinary issues.

Some similarities can be drawn between the concept of "educaccion" in Latin American culture and the concept of "vospitanie", in the culture of immigrants from the FSU. "Vospitanie" contains a range of objectives related to Communist upbringing, including character molding and the development of both the disposition and the will to act in accordance with the values of the state, as well as academic learning (Pearson, 1990). Both teachers and parents were held responsible for the students' education (obrazovanie) and moral upbringing (vospitanie) (Zajda, 1980). The child's conduct had been a very central issue in Soviet education. A respectful and slightly fearful attitude to adult authority was inculcated into Soviet children from the moment they set foot in the educational establishment. The degree of respect (and fear) had been expected to increase with the age and status of older persons (Pearson, 1990).

The differences between Western and Communist orientations towards children's education could explain certain difficulties that immigrant parents from the FSU may experience in a Western country. Zajda (1980) notes that the basic difference between Soviet and American students was their exposure to political socialization. Rigid indoctrination was an inherent characteristic of Soviet education, while in the US, he states, no attempt is generally made to indoctrinate the students. The ever-present moral and political education, so common in the Soviet school, affected all spheres of the pupil's development, contrasting sharply with the moderate political socialization in American schools. Along this line, Ispa (1994) notes that, in contradiction to the educational orientation in the FSU, parents and professionals in the US are discouraged from expecting unquestioning obedience or conformity in children. Yet it must be mentioned that even "liberal" Western schools still enforce and induce compliance with certain behavioral standards such as no hitting or no weapons. The difficulties which immigrants from the FSU may experience around disciplinary issues in their encounters with a Western orientation towards education were identified in a qualitative study conducted by Remennick (2002) with 36 school teachers who emigrated from the FSU to Israel. The teachers were often shocked that they had no taken-for-granted authority in the students' eyes and had to work hard to win their attention and respect. Most participants in the study mentioned the existence of disciplinary problems and lack of respect for the teacher.

\section{Method}

Face-to-face interviews were conducted with a sample of immigrant parents that had moved from Latin America to Toronto, Canada, and with a sample of immigrant parents from the FSU to Israel. The interviews were conducted in the native language of the interviewees. Most of the interviews were conducted at the families' homes. The anonymity of the responses was guaranteed at the beginning of the 
interview. The same instrument was utilized in the two samples. The instrument included questions which focused on conflicts which may have arisen between themselves and professionals, such as teachers, psychologists, social workers, educational advisers, etc., since they have been in Canada or Israel about how to respond to child misbehavior. The interviewees were presented with open-ended questions in which they were asked to:

- describe a conflict situation they had experienced;

- indicate how the professional responded to the misbehavior of their child;

- give their reasons for the disagreement;

- tell how the disagreement was resolved;

- give their opinion about the ways they thought the professional should have responded to the child's misbehavior.

\section{Samples}

The samples included 65 immigrant parents from Latin America and 103 immigrant parents from the FSU. The mean age of the participants in the two samples was around the mid-thirties (Latin American sample, $M=35$; FSU sample, $M=38$ ). The majority of the participants in the two samples were women $(86 \%$ in the Latin American sample and $78.6 \%$ in the FSU sample) and the majority of them had acquired education beyond high school (74\% in the Latin American sample and $84.4 \%$ in the FSU sample). The mean time that the immigrants from Latin American had been in Canada was 6.2 years, and the mean time that the immigrants from the FSU had been in Israel was 6.8 years. The criteria for participation in the two samples were that the parents had arrived in Canada and Israel in the last 11 years and that they had at least one child under the age of 18. The Canadian sample included parents who emigrated from Central and South American countries to Toronto. The Israeli sample included parents who emigrated from the European countries of the FSU to three cities in Israel with a large concentration of immigrants from the FSU. The participants in both samples were recruited primarily through community agencies and social organizations in each location.

\section{Results}

Content analysis was conducted on the responses to the open-ended questions. The reliability of the analysis was ensured by the fact that two researchers analyzed the data from each sample. The main themes from the analysis were related to conflicts that the immigrant parents had with staff in educational systems around disciplinary issues. The results indicated that, in the two samples, participants experienced differences between their expectations about the way in which teachers should handle child misbehavior and the actual behaviors the teachers had engaged in. Parents indicated differences between themselves and teachers with respect to:

(a) the types of misbehaviors which justify intervention by teachers; 
(b) the kind of disciplinary measures which should be used;

(c) the factors that should be considered when deciding about disciplinary actions; and

(d) the lack of sensitivity to the impact of immigration related difficulties on the behavior of children.

A discussion of these themes follows:

\section{(a) The Type of Misbehaviors which Justify Teacher Intervention}

Parents in both samples experienced differences between their perceptions and those of the teachers in their new country about which types of misbehaviors justify teacher intervention. Violent or aggressive behaviors were among the most common examples given by the participants in the two samples as justification for the implementation of disciplinary action by teachers. However, the perspectives of parents in the samples also differed from each other.

Parents from Latin America thought that teachers should be active in stopping the physical incidents (e.g. injurious fights or deadly weapons) among children only in situations where there was real danger. In such situations, they wanted teachers to be stricter and keep the children safe. If the physical incident did not contain any real danger, they thought that the staff in Canadian schools overreacted in their decisions to intervene. The parents disagreed with rigid enforcement of rules by teachers. They disagreed with broad statements such as: "Aggressive behavior will not be tolerated"; or "In children's interactions, the application of physical force, no matter how minor, is never appropriate". In these examples, the differences between the parents' culturally based perceptions and the actions of the Canadian staff about the appropriateness of children's behavior are apparent. The parents felt that the nature of children is to be rambunctious. This is "normal conduct" and such situations do not justify teachers' intervention. It should be noted that these parents, in general, were not calling for fewer rules or general leniency in enforcement. They often stated that students must address teachers in a respectful manner, and wondered why apparently disrespectful forms of address, such as first name usage, were tolerated.

Parents from the FSU considered any aggressive or violent behavior as behavior that should be rightfully subject to intervention and control by teachers. They felt that teachers in Israel had been too tolerant of student misbehavior, such as when there was physical fighting among children. Respondents believed that the educational staff should declare that any physical fighting is forbidden, and when physical incidents occur, the professionals should be more active in their attempt to resolve the conflicts between the children. One of the parents gave the example that "when his child was teased and hit by other children, the teacher was passive in his response. In Russia physical fights were forbidden and one of the most important obligations of teachers was to do something when a child was being hit by other children." 


\section{(b) The Kind of Disciplinary Measures that Should be Used}

Parents in both samples expressed disagreement with the kind of disciplinary measures implemented by teachers in their new countries. There were situations in which parents in both samples thought that the measures used by teachers were too strong and inappropriate. This was primarily with respect to expelling or threatening to expel a child from school. For example, one mother who emigrated from Chile told about a situation in which her daughter was being excluded from her group of friends so she took one of the girls and shook her. They both started crying and her daughter was sent to the office. This was the first incident of this kind for her. The professionals in the school threatened to expel her if it happened again. To this mother, the reaction seemed too drastic, since in her culture these things get resolved between the children.

Parents from the FSU also opposed the measure of expulsion, since they felt that it deprived the child of studies and placed him/her in an unprotected situation, i.e. being unsupervised at home. They claimed that, in Russia, expelling a child was a punishment that was only implemented in extreme situations. They did not consider situations such as fighting among children or smoking in school as a justification for expulsion. In contrast, there were also situations in which parents from the FSU emphasized the need to take stronger measures. One of the parents from the FSU gave examples of measures which teachers should use when a child hits other children in class. she commented: "The teacher should not only ask the child to stop behaving in this way, but, in my opinion, there was a need to take stronger measures, such as telling the child who hit my son, in front of the whole class, that he misbehaved."

\section{(c) Factors that Should Be Considered when Deciding about Disciplinary Actions}

Participants believed that there was a connection between what they viewed as the restricted role of teachers in their new country and their disagreements with the way the teachers handled student misbehavior. Parents in the Latin American sample reported feeling that teachers in Canada were not interested in the child as a person but were simply complying with absolute rules and regulations. Some parents believed in the usefulness of warmth and nurturing behavior on the part of the teachers. They believed that, in some cases, the children's misbehavior was partly due to the teachers being indifferent, cold and impersonal. Their perception was that children needed more humanity in the classroom to be motivated to behave well. One of the parents who emigrated from Peru said:

Teachers in Canada are very indifferent; they don't give the children the love that one would expect from a teacher. They should be like second parents because they spend over 6 hours a day with them. In Peru there are 60 or 50 children in a classroom, but the teacher identifies with each one of them. She knows them, but here the teacher is a person who comes and goes and forgets about them. 
Parents from the FSU also felt that the teachers' role in Israel is restricted too much to academic matters, however, for different reasons. As one of the parents noted: "In Russia, the teacher was responsible for everything in school, and he had to solve every conflict among children. In Israel, the belief is that children can stand up for themselves and adults should not intervene in every situation." The parents valued a broader responsibility of the teachers over the children's behavior with an emphasis on obedience. They objected to situations in which teachers allowed expressions of free will among the children. There were situations in which the teachers permitted the child to miss lessons in a certain subject, to come late to school or to be disrespectful to the teachers. In such situations, the parents felt that the teachers were not fulfilling the disciplinary component of their educational role.

In both samples, the parents noted that the restricted role that teachers take on is also evident in their consideration of which factors to include when deciding about disciplinary actions. Parents in the Latin American sample expressed concern over the teachers making decisions too quickly - they did not consider who was involved, the previous history, possible reasons, situational context and the consequences of the teachers' decisions. They perceived teachers as being overly bureaucratic, impersonal and arbitrary, as well as reacting negatively in such circumstances. For example, a mother who emigrated from Ecuador noted how upset she was that her son had been punished for a minor offence at a time when he was to have received a prize for significant academic achievements. Parents from the FSU were also critical of the factors taken into consideration by teachers when deciding on a punishment. There were parents who thought that there was inequality in the implementation of punishments by teachers. They gave examples of situations of fighting among children in which one child was punished (theirs), and the other child was either not punished at all or did not receive the same level of punishment.

\section{(d) Lack of Sensitivity to Immigration-related Difficulties}

In addition to disagreements about the definitions and types of responses to student misbehavior, parents in both samples felt that there was a lack of consideration regarding immigration-related factors when teachers dealt with misbehavior. The teachers often did not consider the child's being new in the country as contributing to academic and social difficulties. Parents from the FSU described situations in which their children, because they were new in the country, had language problems and, therefore, academic and/or social difficulties in the kindergarten or school, i.e. their ability to participate in classroom activities or to fulfill academic requirements was limited. The parents disagreed with the fact that the professionals' solutions focused on the symptom of the child's difficulties and not on what they considered to be the source of these difficulties-language barriers and other complications arising as a result of immigration. Thus, the parents from the FSU tended to oppose the teachers' solutions, such as transferring the child to another school or leaving the child in the same grade for another year. Parents from Latin America noted that, instead of the teachers seeing the most obvious connections between how the child acts and his/her newcomer status, they tended to resolve the situation without 
relating to the context. For example, they did not consider that the behavioral problems of a child whose parents were born in Nicaragua may have occurred due to the fact that the child was far way from the support and love of his extended family or that a child who had some problems with pronunciation may not need to be referred to speech therapy. A mother from the FSU reported that "when her child started to go to a kindergarten, he didn't know Hebrew (the spoken language in Israel). Therefore, he expressed himself by running and screaming and taking toys from other children. As a response to the child's behavior, the teacher used to close him in a room so that he wouldn't disturb the other children." The mother in this case was upset by the fact that there was no one in the kindergarten who was able to understand the child's social difficulties and communicate with him. The solution did not aim at responding to the source of the difficulties but rather to the symptoms. Several parents in both samples also commented about the lack of communication between the parents and the educational system. Therefore, parents had limited knowledge of their child's academic performance and how he/she behaved in school.

\section{Discussion}

The results of the present study have provided an indication of the common conflicts that immigrant parents experienced in two different countries in their encounters with educational systems, and have furnished evidence of specific disagreements with professionals that each group of immigrants experienced in its new country. The common theme between the samples was that the parents appeared to base their dissatisfactions on the fact that the teacher's perceptions of which behaviors justify disciplinary actions and how to handle misbehavior were different from the expectations they had developed in their country of origin. In the process of acculturation, the expectation most often is that the newcomers will adjust to the mainstream culture. Educators and other authorities in the receiving country generally believe that immigrants have the responsibility of learning to understand the messages of the mainstream culture and not vice versa (Yun Kim, 1988). The findings, however, illustrate the complexity of the acculturation process, since the immigrants do not simply modify their worldview. The perceptions, values and experiences with which the immigrants come continue to play a significant role in their interaction with professionals in their new country, even though they may have been in the new country for several years. (In both samples in this study, the average number of years in the new country exceeded six years.)

Since migration is a social process linking two social systems, in order to reduce barriers between the systems, there is a need to advance reciprocal channels of communication between the systems (one of the objectives of ecological theory). Therefore, there is a need to develop an open, two-way, channel of communication between professionals in educational systems and immigrant parents. In this situation, professionals will become familiar, on the one hand, with the worldview and culture of the immigrants and the possible barriers that they may encounter. On the other hand, parents will have a chance to become familiar with the orientation in 
school towards confronting student misbehavior, as well as gain an opportunity to express disagreement and ask questions.

In our opinion, the ways in which children are being socialized and disciplined (e.g. in schools) need to be reconsidered, including the standards of "appropriateness" articulated by Western professionals. Professionals in educational systems should learn what the role and approaches of educational staff were in the immigrants' country of origin before reacting to immigrant children who misbehave. They also need to develop an understanding about the possible barriers to absorption that immigrants tend to face and the impact that these barriers have on the behavioral problems of immigrant children. By considering the possible clashes between their way of reacting to misbehavior and the cultural background of the immigrants, professionals could address concerns that immigrant parents may have, but are unable to express. For example, the expectation of immigrants from the FSU for more active intervention, or of immigrants from Latin America for a more caring and supportive approach towards their children. This knowledge could also contribute to culturally sensitive assessments of behavioral problems of immigrant children, as well as to the development of culturally sensitive ways of dealing with their misbehavior. Based on such knowledge, professionals may question whether or not the ways in which they respond to misbehavior fit every child, regardless of the cultural context of the child. It could be, for example, that suspending a child from Latin America from school will be perceived within the family in such a way that it will lead to consequences different from the ones expected by the teachers. This is not a plea for special exemptions for immigrant children. However, it is our opinion that "automatic" suspensions may need to be reassessed for many groups of children, including minorities, where the consequences for the child and the family may be unintended or counterproductive in terms of their cultural context. Furthermore, parents' non-lenient approaches may also merit consideration: issues of rigorous standards in such areas as respectful interaction with teachers are perhaps worth reconsidering.

There is also a need to provide parents with a place to explore misunderstandings and express disagreements that they and their children may experience. In addition to helping educational staff to understand immigrant parents better, the parents should be assisted in learning about the role and approach of the teachers in the new countries to various situations, including student misbehavior, as another step in their acculturation process. Gudykunst (1988) claims, based on uncertainty reduction theory, that newcomers' adaptation is essentially a process of reducing the unpredictable elements of the host society by increasing their knowledge about the new environment. Thus, efforts to increase immigrant parents' familiarity with the way in which disciplinary actions are being handled could be a productive approach towards reducing conflicts.

The comparative findings of the two groups of immigrants in this study indicate the significance of examining the issues addressed above and developing adequate responses to the difficulties that parents experience. The findings suggest the need to develop guidelines and programs that will sensitize professionals to the need for variability in handling disciplinary situations. They also argue for an awareness of 
the possibly valid concerns and plausible worldview that underlie the views of immigrant parents regarding discipline. Since the findings demonstrate that the barriers which immigrant parents encounter vary depending on their socio-cultural orientation and that of the educational orientation in their new country, additional research needs to be conducted to expand the knowledge about this issue among diverse groups of immigrants who are coping with the acculturation process in their new countries.

\section{Acknowledgements}

The authors wish to thank the Joint Center of Excellence for Research on Immigration and Settlement in Torono and the Varburg endowment fund in Israel for their support in this research.

Address for correspondence: Dr Ron Shor, Paul Baerwald School of Social Work, The Hebrew University of ferusalem, Mt. Scopus, ferusalem, 91905, Israel; e-mail: msshor@mscc.huji.ac.il

\section{References}

Bernhard, J.K. \& Freire, M. (1999) What is my child learning at school? Culturally contested issues of Latin American children and families? Canadian Ethnic Studies Fournal, 31(3), pp. $72-94$.

BronfEnbrenner, U. (1989) Ecological systems theory. In: VAsta R. (Ed.) Six Theories of Child Development, Vol. 6, pp. 187-250. Greenwich, CT: JAI Press.

Brown, M.T. \& LANDrum-Brown, J. (1995) Counselor supervision: cross-cultural perspectives. In: Ponterotto J.G., Casas J.M., Suzuki L.A. \& Alexander C.M. (Eds) Handbook of Multicultural Counseling, pp. 263-286. California: Sage.

Gallimore, R. \& GoldenberG, C. (1995) Immigrant Latino parents' values and beliefs about their children's education. Culture, Motivation and Achievement, 9, pp. 183-225.

Gopaul-McNicol, S. \& Thomas-Presswood T. (1998). Working With Linguistically and Culturally Different Children: Innovative Clinical and Educational Approaches. Boston: Allyn \& Bacon.

GuARNACCIA P.J. (1997) Ethnicity, immigration and distress among Latinos in the United States. In: Al-Issa, I. \& Tousignant, M. (Eds) Psychopathology, pp. 71-91. New York: Plenum Press.

GUdYKUNST, W.B. (1983) Toward a typology of stranger host relationships. International fournal of Intercultural relations, 7(4), pp. 401-413.

Harwood, R.L., Miller, J.G. \& Irizarry, N.L. (1995) Culture and Attachment: Perceptions of the Child in Context. New York: Guilford Press.

IsPA, J.M. (1994) Child rearing ideas and feelings of Russian and American mothers and early childhood teachers: some comparisons. Advances in Early Education and Care, 6, pp. 235257.

Pearson, L. (1990) Children of Glasnost: Growing Up Soviet. Seattle: University of Washington Press.

REMENNICK, L. (2002) Survival of the fittest: Russian immigrant teachers speak about their professional adjustment in Israel. International Migration, 40(1), pp. 99-119. 
SHOR, R. (1997) The approach of immigrant families from the Former Soviet Union towards child maltreatment, Early Child Development and Care, 134, pp. 61-73.

SLeE, R. (1995) Changing Theories and Practices of Discipline. London: The Falmer Press.

Yun, Kim Y. (1988) Communication and Cross-Cultural Adaptation: An Integrative Theory. Celvedon, UK: Multilingual Matters.

ZaJDA, J.I. (1980) Education in the USSR. Oxford: Pergamon Press. 